\title{
ON THE RATE OF MORTALITY AMONG SELECT LIVES.
}

\section{To the Editor of the Assurance Magazine.}

SiR,-Referring to the Note appended by you to Mr. Berridge's paper in last Number, in which you have been good enough to call attention to a paper of mine, I readily allow that selection as ordinarily practised does not eliminate all unsoundness; bat I am not prepared to admit that if the value of selection at all ages were thoroughly tested and proved, it would establish the accuracy of the theory that in the absence of unsoundness the declension in vitality from early youth (if not from birth) till death is in a progression uniformly accelerated.

I now consider that it may be held as settled that there is no reliable evidence upon which to maintain that there is a greater mortality for one year in a select life from about 40 to 45 than in one from about 20 to 25 ; and that, on the contrary, the evidence before us would lead rather to establish the doctrine that there is no materially greater risk in the assurance of the elder lives for a year.

I think it quite likely that what you designate anomalies in the Carlisle table are really the result of defective and limited observations; and, as a statistical result, the doctrine of the proportion of deaths, among healthy and sick living, increasing from early youth, may be quite true; but I do not think it is likely to be true as a physiological law of the individual or of healthy lives. At all events the general table can have no legitimate bearing on such a question; for I do not think it admits of any question that the mortality for the first year among say 10,000 lives of the ordinary population, of ages similar to those generally assured, is more than twice, and probably about three times, the actual mortality if the lives were properly selected.

I trust that in the greater attention which is now paid to "Experience" by Offices it will be made a point, if not to exhibit the mortality during every year of the duration of policies, at all events to show it during the first year. I feel confident that more real additional knowledge would be obtained by an extensive observation of this limited nature than by a large general Experience over all years. I think we know pretty well how the general Experience stands, but the bearing upon the laws of mortality of the undoubted enormons difference of the mortality among select lives for a year, as compared with that of the general population, has been, comparatively speaking, almost left uninvestigated.

I hope theories may soon give place to ascertained laws, but in the meantime the theory of the mortality among select lives which approves itself most to my mind is, that (while selectness continues) from birth to the prime of manhood-I would not fix the age, but say 35-the mortality diminishes by a lessening ratio, and that after the prime of manhood it increases by an accelerated ratio. All this may be quite consistent with the statistics of the mortality of the general mass of good and bad lives.

I am, Sir,

$$
\text { Yours faithfully, }
$$

Glasgow, August 31, 1865.

WILLIAM SPENS. 